O presente trabalho discutirá as contribuições possíveis ao psicanalista no trabalho junto à deficiência.

Para tanto irá fundar-se sobre as contribuições de Freud, Lacan e principalmente Maud Mannoni, em sua obra "A criança retardada e sua mãe".

Será pensado o impacto que a notícia do nascimento de um filho deficiente pode ter sobre a mãe $\mathrm{e}$ consequentemente sobre sua relação com a criança e ainda a forma como o significante deficiente ou espacial pode repercutir sobre a subjetivação da criança portadora de deficiência física ou mental.

\section{THE SUBJECT AND}

\section{THE DEFICIENCY}

The present work discusses possible contributions to the psychoanalyst while working whit deficient child.

Therefore it will be based on the debates from Freud, Lacan and mainly Maud Mannoni.

It will be thought about the shock of a report of a deficient child's birth and its consequences on the relationship between mother and child. How this significant "deficient / special" could reverberate on the subjectivity of this child, which is handicapped or mentally ill.

\section{O SUJEITO E A \\ DEFICIÊNCIA}

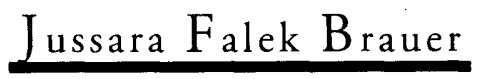

D) sujeito no caso específico da deficiência é um desafio.

A psicanálise em princípio não se aplica ao tratamento da deficiência.

Para compreender isso é preciso que se tenha em vista antes de mais nada as concepções canônicas dentro da psicanálise a este respeito.

Para Freud a condição para que uma pessoa possa submeter-se a uma análise é que ela seja inteligente e capaz de abstração. A psicanálise é em Freud um método terapêutico que se destina ao sujeito neurótico. Freud tem suas razões para formular as coisas desse jeito, já que faz parte do método analítico o trabalho com formações de estrutura metafórica, formações abstratas. Então, se a pessoa não produz esse tipo de formação o analista não tem com o que trabalhar. É graças à capacidade de abstração que o sujeito produz as formações metafóricas que são passíveis de análise.

Jacques Lacan vai contribuir para o campo da psicanálise de várias formas. Sua contribuiçâo maior é, ao menos em minha opinião, o fato de que ele tenha trabalhado na elucidação epistemológica da psicanálise, que

Psicanalista, professora doutora do Instituto de Psicologia da USP 
tenha feito um trabalho de precisão sobre os conceitos forjados por Freud. Ele trabalhou também no tema das psicoses e possibilitou com seu trabalho de precisão conceptual a extensão deste método terapêutico para pacientes psicóticos. Em sua teorização ele distingue três estruturas clínicas: a neurose, a perversão e a psicose, não mencionando a deficiência como estrutura clínica diferenciada.

Poderíamos dizer tudo isso de outra forma. Poderíamos dizer que em Freud o método analítico foi afinado para o trabalho com o paciente neurótico, que Lacan afinou a técnica estendendo-a ao paciente psicótico, e que devemos a Maud Mannoni a abertura que possibilitou estender esse método ao paciente portador de deficiência mental.

É a Maud Mannoni que devemos uma articulação fundamental para que se possa hoje pensar no caso da deficiência em termos psicanalíticos.

Na obra A Criança Retardada E Sua Mãe datada de 1964 Mannoni afirma que no caso da deficiência mental ocorre uma psicotização da relação da criança com sua mãe. Esta obra virá a ser o marco a partir do qual diversos trabalhos com os mais variados tipos de deficiência puderam acontecer, no campo da psicanálise.

Trabalhar analiticamente com a pessoa portadora de deficiência exige do psicanalista o desenvolvimento de uma estratégia clínica específica.

Mannoni faz uma transposição que possibilita isso, ela diz que no caso da deficiência mental há algo que se superpõe. Cria-se um vínculo entre mãe e criança deficiente semelhante àquele que se cria no caso da psicose.

Estabelecendo um paralelo entre a deficiência e a psicose, a hipótese explicativa de Mannoni permite estender os benefícios desta técnica aos pacientes portadores de deficiência.

Pretendo discorrer nesse artigo sobre as decorrências dessa idéia de Mannoni, da qual eu também parti para desenvolver minha pesquisa.

É bom no entanto que fique claro já desde o princípio que sobre a deficiência, ou sobre os diferentes tipos de deficiência a psicanálise nada tem a dizer. Este espaço se abre para outros tipos de intervenção e de compreensão diversos do analítico, onde se tem desenvolvido um saber específico a este respeito.

Quero dizer com isso, por exemplo, que no caso de uma deficiência visual, o psicanalista nada tem a dizer sobre a deficiência visual em si, isto não cabe ao psicanalista. Ao psicanalista cabe pensar sobre as repercussões possiveis desta deficiência sobre o sujeito.

Isto não quer dizer, entenda-se bem, que a psicanálise tenha que retroceder ante a deficiência, mas que sua aproximação se faz de uma forma particular. Vamos pensar um pouco sobre isso.

Em primeiro lugar cabe colocar a pergunta: de que sujeito se trata no caso da psicanálise? E a resposta é clara, trata-se do sujeito 
do inconsciente. A pergunta fundamental aqui é então se no caso da deficiência pode-se postular um inconsciente que nos permita ainda investigar se neste caso ele se constitui de uma forma diferenciada. Aí esta o ponto.

Partindo do pressuposto, enunciado por Lacan, de que o inconsciente não deixa nenhuma de nossas ações fora de seu campo, por ser o inconsciente uma conseqüencia do fato de que o homem fala, podemos perfeitamente supor que a pessoa que possui uma deficiência física tem inconsciente.

Como se pode notar, basta uma afirmação assim tão banal para questionar a tão tímida aproximação da psicanálise com as questões postas pela deficiência.

Ainda cabe salientar que Lacan é um autor estruturalista. Para ele o inconsciente é uma estrutura. Decorre daí que no trabalho analítico o sujeito se dá como sujeito constituído e a partir de uma articulação estrutural. O sujeito ao qual se volta a prática analítica é tomado em sua estrutura, sincronicamente. Ou seja, a psicanálise estrutural trabalha em um eixo temporal onde diferentes cenas da história do sujeito se dispõem simultaneamente. Isto quer dizer que o trabalho analítico deixa de lado o eixo diacrônico, não se ocupa com o desenvolvimento do sujeito ao longo do tempo. Para poder falar em psicanálise, segundo Lacan, é preciso partir do sujeito já constituido, de formações do inconsciente que têm uma estrutura sincrônica, metafórica, tais como o sonho, o lapso, o chiste, o sintoma. A psicanálise, em Lacan, prescinde da noção de desenvolvimento, supera-a. Pelo fato de ter superado a concepção de desenvolvimento em suas formulações, em Lacan já não se vai falar em um sujeito em constituição. Isto tem suas vantagens. Se a psicanálise não pensa o desenvolvimento do inconsciente, tam- bém não permite, em decorrência disso por exemplo falar de um inconsciente deficiente. De um inconsciente que teve um mau desenvolvimento.

Em Lacan não existe inconsciente deficiente, existe inconsciente articulado. Existe posição do sujeito.

Regressão e fixação não são tomados pela psicanálise lacaniana em sua concretude, mas como volteios de linguagem. É o que nos explica este autor no texto Função e campo da fala e da linguagem em Psicanálise. E se a fixação e a regressão são tomados como volteios de linguagem é porque o analista faz delas uma leitura, toma-as como escritura inconsciente, algo que se deve ler e que remete a cenas da história do sujeito. Um comportamento "infantilizado" remete portanto, sob esta perspectiva, a um momento da história em que tal comportamento teria ocorrido.

Resulta dessa concepção o fato de que a psicanálise nada tem a dizer quanto à deficiência, já que seu objeto de estudo é o inconsciente e que ele nada sofre, em tese, com o fato da deficiência física. É em outro sentido que a psicanálise vai tomar a deficiência, vai tomá-la segundo nos sugere Mannoni como um a mais que se sobrepõe à deficiência real. A psicanálise vai assim lidar com a pseudodeficiência do deficiente.

Sem dúvida uma idéia complexa, mas graças à qual podemos estender ao deficiente os benefícios trazidos pela técnica analítica.

Prossigamos.

O inconsciente em Lacan esta ligado à palavra, ao discurso, é uma decorrência do fato de ser o homem um ser de linguagem.

Viver no seio de uma cultura tem suas conseqüências. O fato de que toda cultura repousa sob a base de uma interdição, de uma lei, tem como 
conseqüência o fato de que o homem fale.

Ao ser irremediavelmente separado do seu objeto ele vai recriá-lo como palavra, substituir o objeto perdido pela palavra. O fato de que o homem fala implica em um desvio de suas necessidades, diz Lacan. Ele vai satisfazê-las metaforicamente.

Assim, ao nascer somos acolhidos por uma rede de significantes, de palavras, que nos dão um lugar. Na família tomamos lugar de filho, na escola de aluno, somos loiros ou morenos, portamos determinadas características.

O sujeito toma inconscientemente posição em relação a esses significantes que o acolhem, deixando-se marcar por alguns, e não por outros, e de uma forma precisa.

O sujeito de que trata a psicanálise é indicado pela posição tomada ante os significantes que o marcaram. Ele escreve-se no sonho, no sintoma, no chiste.

Fazer um sintoma inconsciente tomando o significante "deficiente" é superpor à deficiência física uma outra, digamos subjetiva. Esse sintoma revelará metaforicamente a forma como repercute sobre o sujeito sua deficiência real. A deficiência como sintoma inconsciente é ficcional. Representa o sofrimento do deficiente com isso.

Vamos contornando nosso ponto.

Então é possível que subjetivamente o fato de ser deficiente físico represente algo para uma determinada pessoa, que isso tenha concorrido no estabelecimento de sua identificação, que ela tenha se identificado ao significante "deficiente" para além das dificuldades motoras que este problema físico lhe acarretou, que isto signifique ainda outras coisas para essa pessoa. Isso é possível, mas não necessário.

Por exemplo, é possivel que uma criança com uma paralisia cerebral que lhe acarreta alguns poucos problemas motores signifique-se como deficiente a ponto de não falar, de não aprender na escola. Este significante a terá tomado de forma muito mais global do que a lesão real.

Acompanhei certa vez o atendimento de uma menina "surda", que valia-se desta pseudo surdez para não ouvir aquilo que the desagradava. Esta menina tinha apenas um leve prejuízo na audição que não the impedia de ouvir a freqüência da voz humana.

Para apresentar o tipo de deficiência com que a psicanálise trabalha nào é necessário que haja lesão orgânica, apenas um significante com o qual o sujeito se identificou. E vice-versa, a presença de uma lesão orgânica pode não ter como conseqüência esse tipo de identificação. As duas coisas podem no entanto coincidir.

Prossigamos.

A criança com paralisia cerebral ao nascer será colhida pelo significante "deficiente" ou "especial". Este significante lhe dá um lugar na cultura e indica já de início uma série de cuidados que esta criança deve receber e poderá ou não marcá-la como sujeito, portanto.

Como escreve Roland Barthes em seu texto "Aula", a linguagem é uma legislação, a língua é seu código... um idioma se define menos pelo que ele permite dizer, do que por aquilo que ele obriga a dizer.

Não se trata aqui portanto de fazer uma crítica à medicina ou à pedagogia pelo fato de se referirem a um determinado tipo de criança utilizando esse nome. Substituir "deficiente" por "especial" modifica um pouco a situação do ponto de vista da marca. Antes de mais nada indica que a cultura caminhou um pouco ou muito em relação ao que se sabe a respeito desse tipo de fenômeno. Indica que a ciência progrediu neste campo.

A marca que esse significante vai 
imprimir sobre o sujeito vai variar de caso para caso, vai depender da época histórica, da história familiar, etc.

Como em psicanálise trabalha-se com um princípio de causalidade que é a sobredeterminação do sintoma, então já não se pode prever o comportamento que irá advir daí. A causação do comportamento não é linear. O sujeito se calcula a posteriori, quando já posicionado, quando já constituído.

Assim, para que uma criança com paralisia cerebral possa ser tratada convenientemente pelas equipes médicas ao nascer algumas palavras precisam ser ditas sobre ela e a seus pais.

Aqui começamos a entrar no campo definido por Mannoni em suas formulações.

Nós analistas temos algo a dizer sobre os efeitos que podem vir a ocorrer sobre uma mãe a partir da enunciação destes significantes.

O que é para uma mãe saber que seu filho recém nascido porta uma deficiência?

Como sabemos é característico da gravidez um temor que toda mulher tem de gerar uma criança imperfeita. Alguns autores psicanalíticos atribuem esses temores às fantasias edípicas inconscientes comuns a todo ser humano, e às culpas que essas fantasias acarretam. A culpa é tomada aqui como um indicador da fantasia incestuosa. Nesse sentido o advento de um filho deficiente pode ter conseqüências sobre a mãe em um nível psíquico.

A existência real de uma criança portadora de deficiência pode ser lida pela mãe como um castigo, a confirmação de suas fantasias incestuosas, sua puniçâo. Em decorrência disso pode ocorrer algo como a não instituição desta mulher enquanto mãe desta criança portadora de deficiência. Pode ser que ao ouvir do médico que seu bebê é portador de uma paralisia cerebral esta mãe delegue ao médico e suas equipes a condição de bem maternar sua criança, sentindo-se em decorrência disso debilitada e dependente, e precisando recorrer à equipe o tempo todo.

Temos aí um dos tipos de conseqüência sobre o vínculo mãe/criança, onde a mãe destitui-se de seu lugar simbólico de mãe. Abandona psicologicamente sua criança por não poder aí reconhecer suas fantasias incestuosas que emergem no real da deficiência da criança.

Ter um bebe deficiente pode desencadear um episódio de psicose puerperal. Uma despersonalização da mãe sob a forma de um destituir-se do lugar de mãe, ou de um sentir-se incapaz de cuidar de seu bebe. Há portanto que ter cuidado á.

Se destituir-se do lugar de mãe pode criar um tipo de vínculo psicotizante entre mãe e bebê, colar-se à criança é o outro extremo do contínuo que tem as mesmas conseqüências.

Isaías Pessoti relata em seu livro Deficiência Mental: da superstição à ciência a história da marginalização do deficiente em nossa cultura. 
O deficiente pode ocupar um lugar marginal em decorrência de um fenômeno que pode ser explicado agora em termos sociais, por uma necessidade do ser humano de eleger um elemento do grupo sobre o qual irá pesar a exclusão. Segundo Pessoti a deficiência mental já ocupou esse lugar de exclusão social, tendo superado esse impasse através do conhecimento que a ciência desenvolveu em torno do tema. O fato de dispormos hoje desse significante "especial" em substituição a "deficiente" diz desse novo lugar que essas pessoas podem ocupar hoje na cultura em decorrência dos novos conhecimentos que a ciência alcançou a esse respeito. Mas sentimos ainda hoje reflexos desse lugar de exclusão que o deficiente ocupou. Esses reflexos podem acontecer no seio da família.

Decorre daí que dar à luz um filho portador de deficiência pode trazer consigo uma série de sentimentos impronunciáveis que irão permear a criação deste filho. O filho deficiente pode ocupar no interior da família um lugar de exclusão. Vale dizer que não é necessário que haja uma deficiência real para que isso aconteça, mas que no caso da deficiência real as coisas podem tornar-se mais complicadas, a presença da deficiência pode desencadear um processo que de outra forma não ocorreria.

Como dizia, o psicanalista trabalha com fenômenos que são por sua natureza ficcionais. O psicanalista não lida com fenômenos objetivos.

Tudo isso pode acarretar como conseqüência que se engendre entre mãe e filho deficiente uma psicotização da relação agora devida ao fato de que a mãe necessita do filho deficiente para ocupar o lugar de depositário desses sentimentos hostis que ela mesma não suporta reconhecer em si, mas que vê plenamente justificados pela real defi- ciência apresentada pela criança. Mãe e criança permanecerão coladas subjetivamente em decorrência disso. Irão contracenar essa fantasia posta no real do cuidado prestado à deficiência da criança. Cuidar e ser cuidada será o lugar socialmente aceitável onde ficará depositado o sentimento que de outra forma seria inconcebível.

Isso não quer dizer que essas situações que acabo de descrever ocorram necessariamente. Não se trata de uma relação de causa e efeito, por isso só a clínica nos indicará os problemas bem como as soluções para esses problemas. O que descrevo é tomado da experiência clínica, a posteriori.

$O$ que quer dizer afinal uma psicotização da relação?

Na psicose não há pai nem mãe e nem filho. As pessoas no seio da família não ocupam lugares diferenciados.

Freud afirmou que a criança é objeto erótico de seus pais. Ocupar esse lugar faz parte do fato de ter sido desejada por eles. Para a psicanálise o que se transmite aos filhos é um particular modo de desejar. Isso é o que significa perfilhar para a psicanálise.

Então, ocupar esse lugar de objeto desejado tem uma função importante na fundação de um sujeito. Mas se se ocupa esse lugar de objeto então não se pode ocupar um lugar de sujeito, isto é mais ou menos evidente.

É preciso que a criança caia desse lugar de objeto para que ela possa deixar de ser criança, para que ela possa crescer. É necessário que o pai interfira na relação da mãe com sua criança interditando o gozo, interditando-a de certa forma ao ocupar o lugar de objeto de desejo desta mãe e colocá-la também nesse lugar em relação ao seu próprio desejo. O pai o faz como homem, mas também como representante da lei cultural, fazendo da criança seu filho, dando-lhe esse lugar. 
Isso é estruturante para a criança e também para a mulher.

Assim, quando ocorre uma deficiência pode acontecer que ou bem a criança não seja passível de ocupar esse lugar de objeto e portanto de filho, ou que bem que se crie uma relação de gozo entre mãe e criança que não permita que a criança saia desse lugar de objeto, para tornar-se filho.

Principalmente quando se trata de uma deficiência decorrente de paralisia cerebral, quando a criança precisa ser tào manipulada pelas equipes médica e de fisioterapeutas corre-se este risco.

Neste tipo de caso um sinal de alarme pode ser o fato de que o tratamento não venha a promover os efeitos esperados, a criança como que se negue a melhorar, e a mãe contracene com a criança.

É justamente junto a esse tipo de caso que o psicanalista tem algo a contribuir, trabalhando não a paralisia cerebral, mas a relação mãe criança que estando coladas ficam impedidas de seguir sua vida a despeito da deficiência física apresentada pela criança.

\section{REFERENCIAS BIBLIOGRÁFICAS}

MANNONI, M. (1995). A criança retardada e sua mãe, São Paulo: Martins Fontes.

LACAN, J. (1988). "Funçào e campo da fala e da linguagem em psicanálise" In: Escritos, Rio de Janeiro: Zahar.

BARTHES, R. (1980). Aula, São Paulo: Cultrix. PESSOTI, I. (1984). A deficiência mental: da superstiçào à ciência, Sâo Paulo: Queiroz Editor, EDUSP. 